\title{
Lauren subtypes of advanced gastric cancer influence survival and response to chemotherapy: real-world data from the AGAMENON National Cancer Registry
}

Paula Jiménez Fonseca ${ }^{1,25}$, Alberto Carmona-Bayonas ${ }^{\star 2,25}$, Raquel Hernández ${ }^{3}$, Ana Custodio ${ }^{4}$, Juana Maria Cano ${ }^{5}$, Alejandra Lacalle ${ }^{6}$, Isabel Echavarria ${ }^{7}$, Ismael Macias ${ }^{8}$, Monserrat Mangas ${ }^{9}$, Laura Visa ${ }^{10}$, Elvira Buxo ${ }^{11}$, Felipe Álvarez Manceñido ${ }^{12}$, Antonio Viudez ${ }^{6}$, Carles Pericay ${ }^{8}$, Aitor Azkarate ${ }^{13}$, Avinash Ramchandani ${ }^{14}$, Carlos López ${ }^{15}$, Eva Martinez de Castro $^{15}$, Ana Fernández Montes ${ }^{16}$, Federico Longo ${ }^{17}$, Rodrigo Sánchez Bayona ${ }^{18}$, Maria Luisa Limón ${ }^{19}$, Asun Diaz-Serrano ${ }^{20}$, Alfonso Martin Carnicero ${ }^{21}$, David Arias ${ }^{16}$, Paula Cerdà ${ }^{22}$, Fernando Rivera ${ }^{15}$, Jose Maria Vieitez ${ }^{1}$, Manuel Sánchez Cánovas ${ }^{2}$, M Garrido ${ }^{23}$ and $\mathrm{J}$ Gallego ${ }^{24}$ on behalf of the AGAMENON study group

BACKGROUND: The choice of chemotherapy in HER2-negative gastric cancer is based on centre's preferences and adverse effects profile. No schedule is currently accepted as standard, nor are there any factors to predict response, other than HER2 status. We seek to evaluate whether Lauren type influences the efficacy of various chemotherapies and on patient overall survival $(\mathrm{OS})$.

METHODS: We have conducted a multicenter study in 31 hospitals. The eligibility criteria include diagnosis of stomach or gastroesophageal junction adenocarcinoma, HER2 negativity, and chemotherapy containing 2-3 drugs. Cox proportional hazards regression adjusted for confounding factors, with tests of 'treatment-by-histology' interaction, was used to estimate treatment effect.

RESULTS: Our registry contains 1303 tumours analysable for OS end points and 730 evaluable for overall response rate (ORR). A decrease in ORR was detected in the presence of a diffuse component: odds ratio 0.719 ( $95 \%$ confidence interval ( $\mathrm{Cl}$ ), 0.525-0.987), $P=0.039$. Anthracycline- or docetaxel-containing schedules increased ORR only in the intestinal type. The diffuse type displayed increased mortality with hazard ratio $(H R)$ of $1.201(95 \% \mathrm{Cl}, 1.054-1.368), P=0.0056$. Patients receiving chemotherapy with docetaxel exhibited increased OS limited to the intestinal type: HR $0.65(95 \% \mathrm{Cl}, 0.49-0.87)$, $P=0.024$, with no increment in OS for the subset having a diffuse component. With respect to progression-free survival (PFS), a significant interaction was seen in the effect of docetaxel-containing schedules, with better PFS limited to the intestinal type subgroup, in the comparison against any other schedule: HR 0.65 (95\% Cl, 0.50-0.85), $P=0.015$, and against anthracycline-based regimens: HR 0.64 (95\% Cl, 0.46-0.88), $P=0.046$.

CONCLUSIONS: As a conclusion, in this registry, Lauren classification tumour subtypes predicted survival and responded differently to chemotherapy. Future clinical trials should stratify effect estimations based on histology.

\footnotetext{
*Correspondence: Dr P Jiménez Fonseca; E-mail: palucaji@hotmail.com

${ }^{25}$ These authors contributed equally to this work.
}

Received 25 April 2017; revised 19 June 2017; accepted 4 July 2017; published online 1 August 2017

(C) 2017 Cancer Research UK. All rights reserved 0007-0920/17 
Advanced gastric cancer (AGC) is a complex, heterogenous entity that encompasses tumours with varying histologies, molecular profiles, and behaviours. Lauren's histological classification distinguishes between intestinal type (IT), with the presence of gland formations, and diffuse type (DT), with a pattern of poorly cohesive cells, high invasiveness, and on occasion, the presence of signet ring cells. This histological classification is relevant from a prognostic, epidemiological, and pathogenic perspective (Lauren, 1965). The two histotypes differ in their clinical and molecular features to the point of representing distinct entities (Shah et al, 2011; Tan et al, 2011; Ma et al, 2016). Thus, DT tumours are often genomically stable, although they tend to harbour characteristic mutations in genes that participate in adhesion, chromatin integrity, or cell motility, such as the E-cadherin gene (CDH1) and Ras homologue gene family, member A (RhoA), as well as fusions involving the gene that codes for claudin-18 and Rho GTPase activating protein 6 (CLDN18-ARHGAP6), among others (Cancer Genome Atlas Research Network, 2014). In contrast, IT tumours exhibit aneuploidy or other genetic features more frequently, the most relevant ones being certain mitotic and signalling pathways, such as human epidermal growth factor receptor 2 (HER2) (Hofmann et al, 2008; Cancer Genome Atlas Research Network, 2014).

In cancers overexpressing or amplifying HER2, the combination of cisplatin-fluoropyrimine-trastuzumab is considered to be the treatment of reference and is, to date, the schedule that has achieved the best results with median overall survival (mOS) of 13.8 months (Bang et al, 2010). In HER2-negative cancers, different combinations of platin with fluoropyrimidine attain mOS rates that rarely exceed 12 months, and overall response rates (ORR) that range between 35 and $45 \%$. The addition of a third cytotoxic (epirubicin or docetaxel) is not able to reach mOS $>12$ months, while increasing toxicity (Wagner et al, 2010). At present, the choice of treatment schedule for HER2-negative tumours is based on the centre's preferences and adverse effects profile, with no chemotherapy deemed standard across-the-board (Duo-Ji et al, 2017). Therefore, identifying factors that modify response to drugs and guide clinical decisions continues to be a pressing concern.

Despite the fact that the Lauren classification is more than 50 years old (Lauren, 1965), the predictive effect of each histological subtype on various end points related to the efficacy of chemotherapy has yet to be definitively dilucidated, since most important pivotal trials in western populations did not report preplanned subgroup analyses based on these criteria. This has led to these pathological subtypes being treated equally (Van Cutsem et al, 2006; Cunningham et al, 2008). In the case of AGC, most data available from Asian populations suggest that histological heterogeneity correlates to sensitivity to specific drugs, opening the door to personalised therapies (Koizumi et al, 2008, 2014; Boku et al, 2009; Narahara et al, 2011). However, the evidence is still weak, with interaction tests that were often non-significant or simply not reported, as addition to having limited sample sizes.

Against this background, the aim of this study has been to ascertain whether Lauren type modified response to several chemotherapy regimens used in clinical practice. To this end, 'real world' data from a National AGC Registry have been used.

\section{MATERIALS AND METHODS}

Patients. All the patient data are from a national registry of consecutive cases of AGC that began recruitment in 2014 (AGAMENON Study), with the participation of one Chilean and 30 Spanish centres. The main characteristics of this registry, method, and data collection criteria have been previously reported (Carmona-Bayonas et al, 2016, 2017; Jiménez-Fonseca et al, 2016;
Custodio et al, 2017). Briefly put, AGAMENON is a noninterventionist registry sponsored by the investigators themselves; the diagnostic and therapeutic patterns were those implemented according to the clinical practice of each centre. The data are gathered by means of a web-based data collection tool (http:// www.agamenonstudy.com/). This tool has multiple filters and a system of queries, to ensure the reliability of the data in real time. The researchers are systematically instructed on the requirements of the registry and the information is regularly monitored remotely and the cases are closed after they are validated.

Basically, eligibility criteria for OS end points include a histologically confirmed diagnosis of unresectable, locally advanced, or metastatic adenocarcinoma of the stomach or gastroesophageal junction; furthermore, patients must have received a minimum of one course of polychemotherapy containing two or three drugs. The population that is eligible for objective tumour response analysis also required the presence of initially measurable disease, with at least one objective evaluation at three months, according to Response Evaluation Criteria in Solid Tumors (RECIST 1.1). Adenocarcinomas of the oesophagus were excluded from this analysis, despite their molecular similarities with gastric cancer with chromosomal instability (Cancer Genome Atlas Research Network, 2017), given the epidemiological and molecular differences, and specific treatment patterns. We also excluded HER2-positive tumours (immunohistochemistry $3+$ or $2+$, and fluorescent in situ hybridisation-positive), as they represent a different biological reality with standard treatment. Other exclusion criteria were $<6$ months since the end of adjuvant or perioperative treatment, the presence of other synchronous primary cancers, and the absence of at least 3 months of follow-up (except for the patients who died during this period). The study was approved by a multicenter Research Ethics Committee. All patients still alive at the time of data collection provided written, signed, informed consent.

Variables. The primary end point of this study was ORR as per RECIST 1.1 criteria locally evaluated according to the usual practice at the centre. Secondary end points were OS and progression-free survival (PFS) defined as the time between treatment initiation and tumour progression or all-cause mortality, censoring patients lost to follow-up. The chemotherapy regimens used in each histological type are those that represent patterns of realworld clinical practice at the various centres (Supplementary Annex Table 1). The following strata were established for pairwise comparisons of chemotherapy schedules: two-agent with cisplatin-fluoropyrimidine, two-agent containing oxaliplatinfluoropyrimidine, regimens with irinotecan, three-agent with anthracyclines, and docetaxel-containing schedules. The Lauren classification was locally assessed as routinely performed at each centre, and no centralised review was carried out. Tumours with signet ring cells were classified as diffuse according to International Agency for Research on Cancer (IARC) criteria (Hamilton and Aaltonen, 2000). As possible confounding factors, we considered 17 routinely available baseline clinical-pathological variables proven to predict survival in at least one previous publication (Custodio et al, 2017). In addition, univariate analyses were performed to verify that these variables had prognostic significance and to exclude other potential factors (Supplementary Annex Table 2).

Statistical methods. The Cochran-Mantel-Haenszel (CMH) test was used to evaluate the null hypothesis of ORR being independent of Lauren type and controlling for kind of chemotherapy. The heterogeneity across sites was evaluated with the I2 statistic. The homogeneity of the odds ratio for each treatment was analysed by the Breslow-Day test. To assess the effect of each treatment (hazard ratio (HR)) for each end point in subgroups defined by the Lauren classification, the Cox proportional hazards regression was used, adjusted for interaction tests (treatment type-by-Lauren), and 
the previously named confounding factors. Interaction tests make it possible to detect whether the observed effect of treatment is significantly different in each Lauren subtype (Simon, 1982; Barraclough and Govindan, 2010). All statistical assessments were two-sided and $P$-values $<0.05$ were deemed significant. The Holm-Bonferroni method was used for multiple comparisons. Prior data from the literature indicate that the ORR for IT tumours is $\sim 45 \%$. If the true ORR for DT tumours were $25 \%$ lower, some 626 patients would be required, using $\chi^{2}$ statistics in order to reject the null hypothesis that responses in those subtypes are equal, with a statistical power of $80 \%$, and a Type I error probability of $5 \%$ (Fleiss et al, 1980). Statistical analyses were performed using RStudio (RStudio, Inc., Boston, MA, USA), including survival, base, epitools, and forest plot packages.

\section{RESULTS}

Patients. At the data cutoff (June 2017), the registry comprised 2203 patients treated with first-line chemotherapy between January
2008 and March 2017, of which 1303 were evaluable for survival end points and 730 for tumour response. The patient selection process is presented in Figure 1. It is worth noting that the exclusion of HER2-positives (281 tumours) conditions the distribution of the Lauren histological types in this series $(37 \%$ IT, $50 \%$, DT, and 13\% not classified). The analysis of histological results by centres reveals the presence of slight heterogeneity (I2 $=25 \%, P=0.115) \quad$ (Supplementary Annex Table 3). The remaining baseline characteristics of the cohort are displayed in Table 1 . The disease was initially categorised as measureable by RECIST 1.1 criteria in $71 \%$, while $56 \%$ had measurable disease at baseline and evaluable at 3 months. Briefly put, the schedules were: oxaliplatin-fluoropyridines (35\%), anthracycline-containing triplets (26\%), docetaxel-based schedules (15\%), cisplatinfluoropyrimidines (15\%), irinotecan-based regimens (2\%), and other (5\%) (Supplementary Annex Table 1). As regards the docetaxel-based schedules, $76 \%$ (145 of 197) were triple-agent regimens.

ORR according to Lauren histological type. A total of 730 patients had measurable and response-evaluable disease (Figure 1).

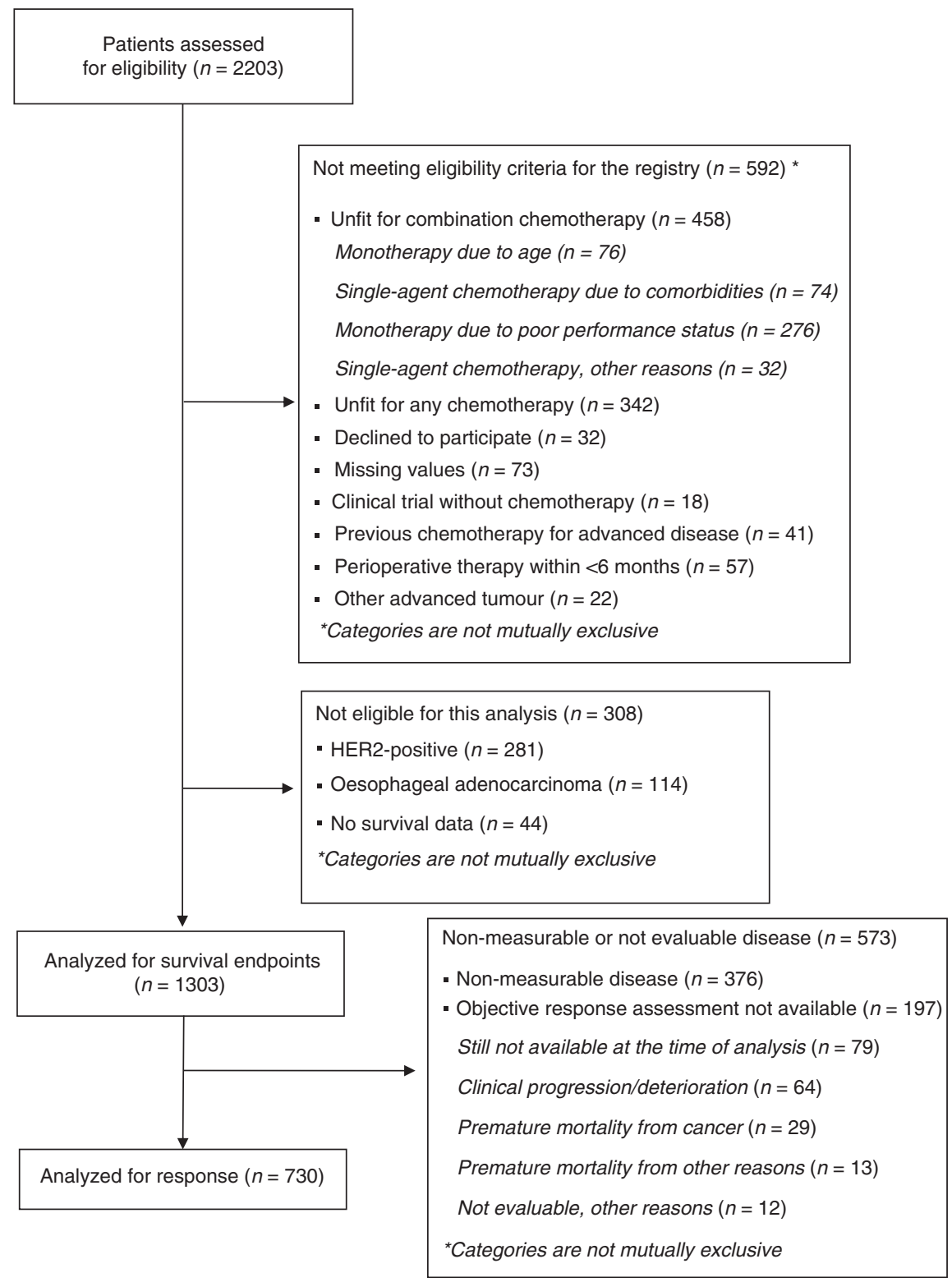

Figure 1. Flowchart of patients in the registry. HER2 = human epidermal growth factor receptor 2. 
Table 1. Baseline characteristics of the patients analysed for survival-related end points

\begin{tabular}{|c|c|}
\hline Characteristics & $\begin{array}{l}\text { All patients, } \\
n=1303\end{array}$ \\
\hline Sex, male & $880(68 \%)$ \\
\hline Age, mean \pm s.d. & $63 \pm 12$ \\
\hline Albumin, $<3.5 \mathrm{~g} \mathrm{dl}^{-1}$ & $317(24 \%)$ \\
\hline ECOG-PS $\geqslant 2$ & $188(14 \%)$ \\
\hline $\begin{array}{l}\text { Primary tumour site } \\
\text { Gastroesophageal junction } \\
\text { Stomach }\end{array}$ & $\begin{array}{r}138(11 \%) \\
1165(89 \%)\end{array}$ \\
\hline Stage at diagnosis, metastatic & $1236(95 \%)$ \\
\hline Surgery of primary tumour & $494(38 \%)$ \\
\hline $\begin{array}{l}\text { Chemotherapy schedules } \\
\text { Oxaliplatin-based } \\
\text { Anthracycline-based } \\
\text { Cisplatin-based } \\
\text { Docetaxel-based } \\
\text { Irinotecan-based } \\
\text { Other }\end{array}$ & $\begin{array}{c}459(35 \%) \\
344(26 \%) \\
191(15 \%) \\
213(16 \%) \\
29(2 \%) \\
67(5 \%)\end{array}$ \\
\hline Prior perioperative treatment & $155(12 \%)$ \\
\hline $\begin{array}{l}\text { Lauren classification } \\
\text { Intestinal } \\
\text { Diffuse } \\
\text { Indeterminate }\end{array}$ & $\begin{array}{l}482(37 \%) \\
652(50 \%) \\
169(13 \%)\end{array}$ \\
\hline $\begin{array}{l}\text { Histological grade } \\
\text { Grade } 1 \\
\text { Grade } 2 \\
\text { Grade } 3 \\
\text { Not available }\end{array}$ & $\begin{array}{l}102(8 \%) \\
340(26 \%) \\
580(44 \%) \\
281(22 \%)\end{array}$ \\
\hline $\begin{array}{l}\text { Presence of signet ring cells } \\
\text { No signet ring cells } \\
\text { Signet ring cells }(<50 \%) \\
\text { Signet ring cells }(\geqslant 50 \%) \\
\text { Signet ring cells present with unknown percentage } \\
\text { Not available }\end{array}$ & $\begin{array}{l}660(50 \%) \\
103(8 \%) \\
152(12 \%) \\
202(16 \%) \\
186(14 \%)\end{array}$ \\
\hline $\begin{array}{l}\text { Site of metastases } \\
\text { Liver } \\
\text { Peritoneum } \\
\text { Bone } \\
\text { Lung }\end{array}$ & $\begin{array}{c}414(32 \%) \\
641(49 \%) \\
128(10 \%) \\
98(8 \%)\end{array}$ \\
\hline $\begin{array}{l}\text { Tumour measurability } \\
\text { Only non-measurable disease } \\
\text { Measurable disease } \\
\text { Measurable disease \& response assessment } \\
\text { available at } 3 \text { months }\end{array}$ & $\begin{array}{l}376(29 \%) \\
927(71 \%) \\
730(56 \%)\end{array}$ \\
\hline $\begin{array}{l}\text { Abbreviations: ECOG-PS = Eastern Cooperative Group Perform } \\
\text { per decilitre. }\end{array}$ & tus; $\mathrm{gdl}^{-1}=$ grams \\
\hline
\end{tabular}

The 3-month RECIST 1.1 evaluation in this group revealed: complete response in $16(2 \%)$, partial response in $306(42 \%)$, stable disease in 249 (34\%), and tumour progression in 159 (22\%). When data from different schemes were factored in and pooled, a decrease in ORR was detected in the presence of a diffuse component: $\mathrm{CMH}$ common odds ratio 0.719 (95\% confidence interval (CI), $0.525-0.987), P=0.039$. In a sensitivity analysis, when only schedules with anthracycline or docetaxel were examined, the probability of response in diffuse tumours was also significantly decreased: common odds ratio 0.522 (95\% CI, $0.323-$ $0.843), P=0.008$.

The breakdown of ORR (complete plus partial response) data by chemotherapy is shown in Figure 2. In this analysis, no overall heterogeneity was observed regarding ORR in each Lauren type across chemotherapy strata (Breslow-Day test, $\chi^{2}=9.502, \mathrm{df}=5$, $P=0.091)$. Exceptions to this were the superior ORR achieved in intestinal tumours by anthracycline-containing combinations vs doublets $(60 \%$ vs 37\%, $P=0.0048)$, and docetaxel-based regimens (61\% vs 37\%, $P=0.012$ ). However, the remaining pairwise comparisons failed to detect other significant differences (Table 2). Specifically, there was no signal on a preferred schedule for response in diffuse histology.

Evaluation of survival-related end points according to Lauren histological type. Survival-related end points were analysable in 1303 patients from this registry. At the time of data cutoff, 1076 deaths $(83 \%)$ had been recorded, with a mOS of 10.2 months $(95 \%$ CI, 9.7-10.7). Prognosis varies depending on the histological subtype, with mOS 11.0 months (95\% CI, 10.3-12.1) for IT; 9.3 months (95\% CI, 8.3-10.3) for DT, and 10.1 months (95\% CI, 8.511.1) for unclassified tumours (log-rank test of $\chi^{2}=7.7, \mathrm{df}=2$, $P=0.021$ ). Consequently, in comparison to IT (the reference group), increased risk of death is noted with a HR of $1.201(95 \%$ CI, 1.054-1.368) for DT $(P=0.0056)$; differences were not significant for unclassified tumours, HR 1.092 (95\% CI, $0.902-$ 1.322), with $P=0.366$.

The HR for OS of chemotherapy in Lauren type subgroups was then analysed, adjusting for confounding factors and corrected for multiple hypothesis tests (see Forest Plot in Figure 3). The lack of significant variations is apparent in the estimation of effect in those histological types, in both the comparison of oxaliplatin-containing double-chemotherapy $v s$ cisplatin, as well as in the comparison between schedules with and without anthracyclines. In contrast, the interaction tests revealed an observable subgroup effect in OS benefit for schedules incorporating docetaxel. In comparison to the rest of the population, patients receiving chemotherapy with docetaxel exhibited increased mOS limited to IT: HR 0.65 (95\% CI, $0.49-0.87), P=0.024$.

On the other hand, at the data cutoff point, 1040 events of progression had been recorded in 1303 patients (80\%). All told, no significant differences were detected in MPFS based on Lauren type: 6.1 months (95\% CI, 5.6-6.5) for IT, 6.2 months (95\% CI, 5.6-6.5) for DT, and 5.4 months (95\% CI, 4.4-6.3) for unclassified tumours, with a log-rank test of $\chi^{2}=3.3, \mathrm{df}=2, P=0.191$. In the case of the effect of chemotherapy on PFS for each subgroup, the difference in estimations is reported in Figure 4. In line with the survival analysis, no differences were detected in subgroups (HR for PFS) for two-agent chemotherapy based on oxaliplatin or cisplatin; likewise, the same is true for with or without anthracyclines. In contrast, a significant interaction was seen in the effect of docetaxel-containing schedules, with significantly better PFS limited to the IT, in the comparison against any other schedule: HR 0.65 (95\% CI, 0.50-0.85), $P=0.015$, and in comparison to anthracycline-based regimens: HR 0.64 (95\% CI, $0.46-0.88$ ), $P=0.046$ (Figure 4).

\section{DISCUSSION}

In the last years, several studies have examined the issue of whether Lauren's histological classification, which divides gastric tumours into IT and DT, is useful when individualising therapies in gastric cancer (Tan et al, 2011; Ma et al, 2016; Yong; et al, 2017). This is no trivial consideration, as highlighted by pivotal studies in AGC carried out in Asian countries. Attention to the Lauren classification as a possible predictive variable derives from the better understanding of the underlying molecular base in IT/DT types (Shah et al, 2011; Tan et al, 2011; Lei et al, 2013; Cancer Genome Atlas Research Network, 2014; Cristescu et al, 2015), the absence of any recent advances, and the promising perspectives of certain exploratory subgroup analyses in clinical trials (Koizumi et al, 2008, 2014; Ajani et al, 2009; Boku et al, 2009; Narahara et al, 2011). In the genomic and molecular characterisation of gastric cancer reported by the Cancer Genome Atlas (TCGA), the 


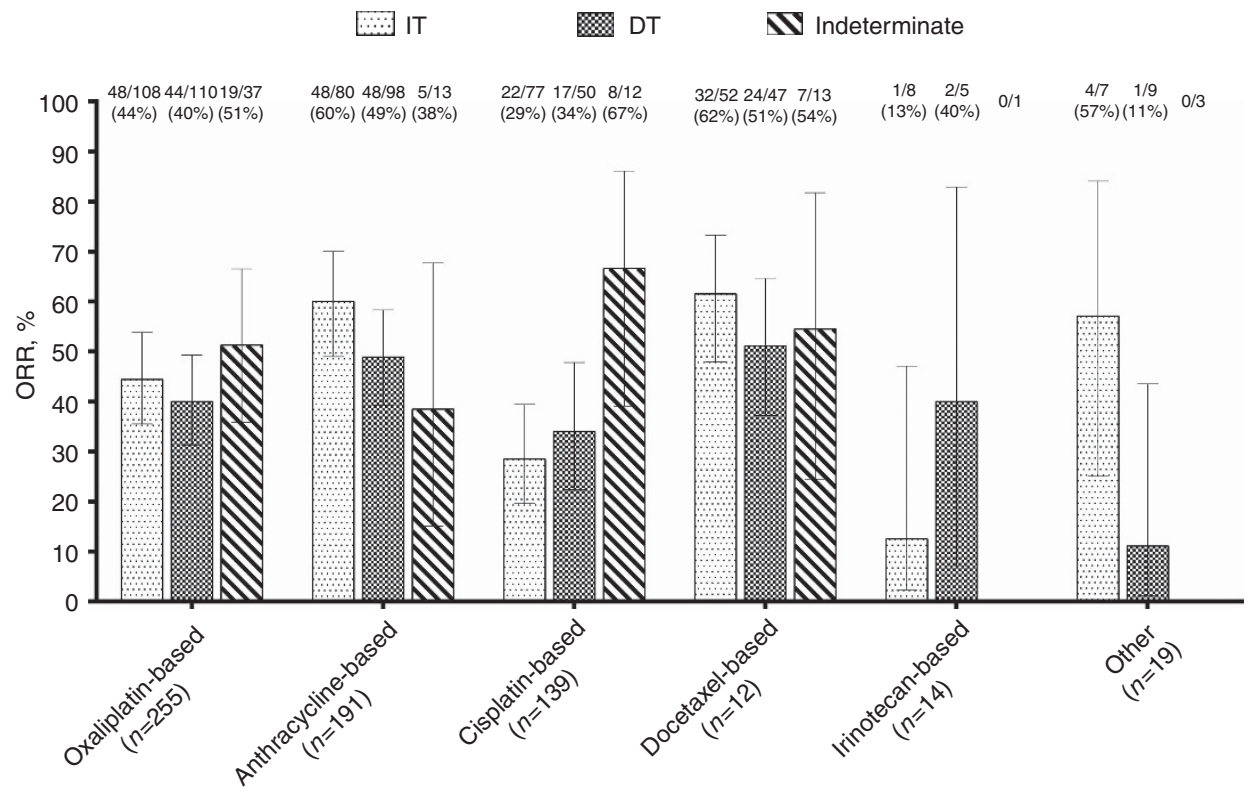

Figure 2. Overall response rate according to chemotherapy regimens and Lauren histological type. Data set: subjects with response-evaluable (at 3 months) and initially measurable disease $(n=730)$. DT = diffuse type; IT = intestinal type; ORR=overall response rate.

\begin{tabular}{|c|c|c|c|}
\hline & & ORR & $P$-value \\
\hline \multirow[t]{2}{*}{ Oxaliplatin vs cisplatin doublets } & IT & $44.4 \%$ vs $28.5 \%$ & 1.0000 \\
\hline & DT & $40.7 \%$ vs $34.0 \%$ & 0.1692 \\
\hline \multirow{2}{*}{$\begin{array}{l}\text { Anthracyclines vs platinum- } \\
\text { fluoropyrimidine doublets }\end{array}$} & IT & $60.0 \%$ vs $37.5 \%$ & 0.0048 \\
\hline & DT & $40.8 \%$ vs $36.7 \%$ & 1.0000 \\
\hline \multirow{2}{*}{$\begin{array}{l}\text { Docetaxel vs platinum- } \\
\text { fluoropyrimidine doublets }\end{array}$} & IT & $61.5 \%$ vs $37.5 \%$ & 0.0124 \\
\hline & DT & $51.0 \%$ vs $36.7 \%$ & 0.3796 \\
\hline \multirow[t]{2}{*}{ Docetaxel vs anthracyclines } & IT & $61.8 \%$ vs $60.0 \%$ & 0.8597 \\
\hline & DT & $51.0 \%$ vs $40.8 \%$ & 0.9791 \\
\hline
\end{tabular}

Abbreviations: $\mathrm{DT}=$ diffuse type; $I T=$ intestinal type; $\mathrm{ORR}=$ overall response rate. Data set: subjects with response-evaluable (at 3 months) and initially measurable disease $(n=730)$. Test used: $\chi^{2} ; P$-values were corrected using the Holm-Bonferroni method.

genomically stable subtype was enriched for the DT variant, whereas tumours with chromosomal instability corresponded partly with ITs; this classification might be basic for treatment decisions in the future (Cancer Genome Atlas Research Network, 2014). In an attempt to contrast the degree to which this hypothesis holds up in the 'real world', we have used a multicenter registry, with the aim of gauging the impact histological characteristics have on the estimations of effect of various combinations of chemotherapy administered to patients with HER2-negative AGC.

We have found that IT tumours are more chemosensitive (greater ORR), particularly when three-agent regimens are used. However, this finding was not clearly translated into survivalrelated outcomes, except for docetaxel-containing schedules. In fact, one of the most substantial discoveries in this work was the benefit observed in both PFS as well as OS for schedulescontaining docetaxel $v s$ other chemotherapies in IT tumours. This finding is consistent with the recently published data from the FLOT-AIO4 trial that concluded that the perioperative use of FLOT is more active, for example, it induced more disease remissions than ECF/ECX (epirubicin, cisplatin, and fluorouracil or capecitabine) in patients with operable gastric cancer, having pronounced activity in IT vs DT (Al-Batran et al, 2016). This conclusion is also in line with the result of another neoadjuvancy study, the NeoFLOT trial, a phase II that also found FLOT was more active in predominantly IT, as quantified in terms of complete or near complete ORR (Schulz et al, 2015). In turn, our data are compatible with the results of the V325 clinical trial that concluded that adding docetaxel to cisplatin-fluorouracil significantly improved OS, although this analysis was not stratified based on histology (Van Cutsem et al, 2006). Nevertheless, given the toxicity of these schedules, it would be worthwhile to corroborate the risk-benefit in DT in future clinical trials.

Insofar as triple-agent regimens are concerned, this analysis constitutes a refinement of other previous reports from the AGAMENON registry in which it was suggested that three-drug regimens (both epirubicin- and docetaxel-based) were associated with a discreet increase in OS: HR 0.84 (95\% CI, 0.72-0.98; $P=0.035$ ) (Carmona-Bayonas et al, 2016), although this beneficial effect disappeared when the comparison was confined to anthracyclines-based triplets $v s$ platin-fluoropyrimidine doubleagent therapies: HR 0.91 (CI, 95\%, 0.76-1.08; $P=0.226$ ) (Carmona-Bayonas et al, 2017). Indeed, here we confirm that the absence of incremental benefit in survival-related outcomes apparently involved with the addition of anthracyclines to platin-fluoropyrimidine double-agent therapies does not vary significantly according to the underlying histological subtype. Our series illustrate that more intense schedules with docetaxel increase PFS, compared to schedules with anthracyclines; however, we propose the hypothesis that this benefit is limited to the IT subgroup and it is possible that it does not occur in DT, which would have to be corroborated in the future.

As for individuals who received only double-agent schedules, the data obtained about patients with measurable and responseevaluable disease in our registry were unable to provide statistical evidence that the oxaliplatin-fluoropyrimidines regimens yielded higher ORR in IT than cisplatin-fluoropyrimidine. In this regard, a small, phase II trial have recently suggested that microarray-based tumour molecular profiling is predictive of differential platin sensitivity (Yong; et al, 2017). The method consisted of testing a genetic signature developed in a cohort from the National Cancer Centre of Singapore that classified tumours into two genomic subtypes, one intestinal and another diffuse, with greater sensitivity 


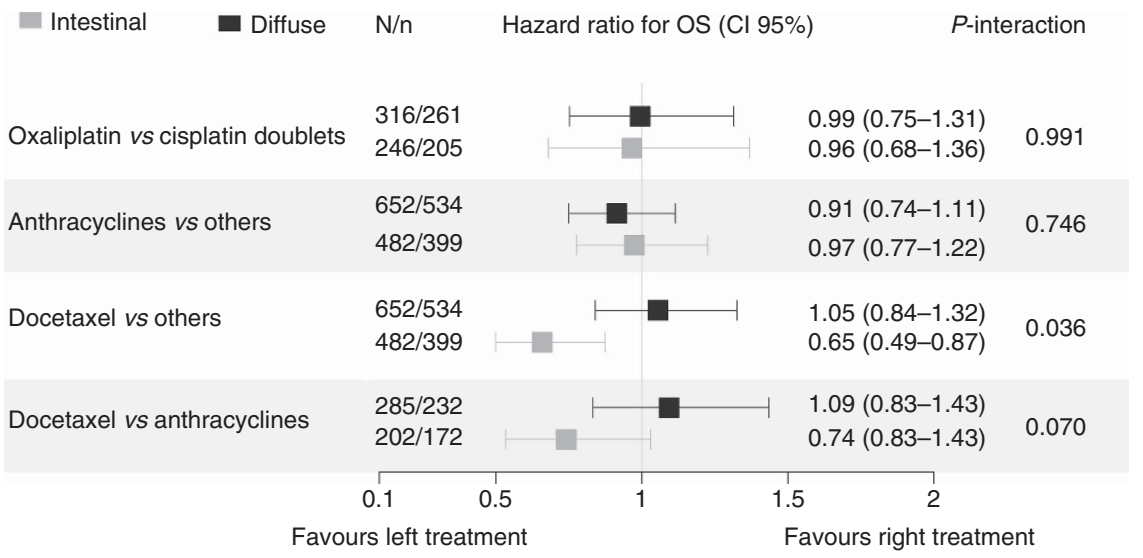

Figure 3. Forest plot exhibiting the effect of treatment subgroups (hazard ratio for overall survival) according to Lauren histological type. Data set used: patients without indeterminate tumours $(n=1134)$. Test used: HRs are derived from multivariable Cox proportional hazards regression adjusted for gender, ECOG-PS, albumin, histological grade, neutrophil-to-lymphocyte ratio, stage, ascites, bone metastases, lung metastases, and number of metastatic sites (see Materials and Methods section); the effect of subgroups is based on the interaction between Lauren classification (IT \& DT) and chemotherapy. The Holm-Bonferroni method was used for multiple comparisons. HR= hazard ratio; $N / n=$ population/events; OS = overall survival.

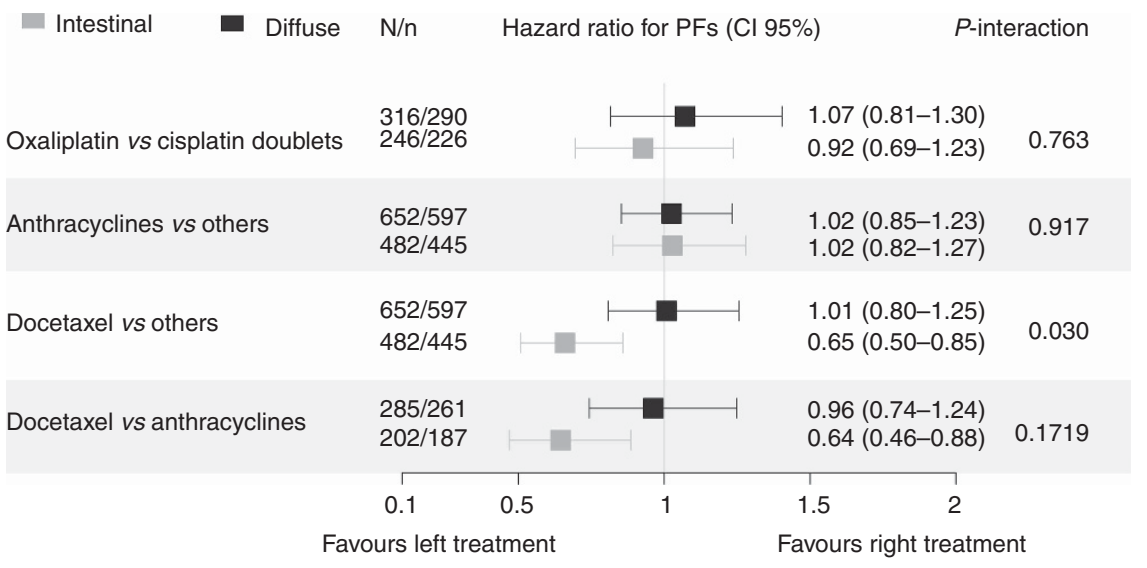

Figure 4. Forest plot exhibiting the effect of subgroups del treatment (hazard ratio for progression-free survival) according to Lauren histological type. Data set used: patients without indeterminate tumours $(n=1134)$. Test used: HRs are derived from multivariable Cox proportional hazards regression adjusted for ECOG-PS, albumin, neutrophil-to-lymphocyte ratio, ascites, bone metastases, lung metastases, and number of metastatic sites (see Materials and Methods section); the effect of subgroups is based on the interaction between Lauren classification (IT \& DT) and chemotherapy. The Holm-Bonferroni method was used for multiple comparisons. HR= hazard ratio; $N / n=$ population/events; $\mathrm{PFS}=$ progression-free survival.

to oxaliplatin and cisplatin, respectively (Tan et al, 2011). Nevertheless, concordance with the Lauren histological classification in this study was only $65 \%$; hence, its correspondence with our data is questionable. Furthermore, for survival end points, we have not either detected interactions between the type of platin and histology. In any case, we have not been able to demonstrate greater sensitivity to cisplatin in the DT; our overall impression is that clinical-molecular correlations require more extensive clinical validations.

Insofar as the generalisability and reproductibility of these results are concerned, one of the most salient characteristics of our series is the exclusion of HER2-positive tumours, which have distinctive traits: (1) a single, standard treatment with platin-fluoropyrimidinetrastuzumab (Bang et al, 2010) and (2) preponderance of IT (Huang et al, 2013). These aspects condition the histological distribution in our cohort that has a higher rate of diffuse tumours than typically reported in series of gastric cancer not selected on the basis of HER2 status (Lauren, 1965). The other characteristic worthy of note having to do with the comparability of results is that chemotherapy activity was only assessed in patients with measurable disease, which eliminates systematic errors, but prevents the evaluation of response in DT tumours with only unmeasurable, peritoneal miliary dissemination, which presumably constitutes less chemosensitive diseases (Yoon et al, 2016).

Our study has certain limitations. Some of them are contingent to any result based on subgroup analyses, for example, increased type II errors when the alternative hypothesis is correct (Barraclough and Govindan, 2010). Therefore, this kind of report must necessarily be interpreted with caution. Although the HolmBonferroni method is used to control the family-wise error rate due to multiple comparisons, it also reduces statistical power; thus, the existence of small differences cannot be ruled out. Other limitations are common to all analyses of registries with 'real world' data. Most of the data are retrospective with the inherent issues of accuracy, although in this case, the end points used (ORR, PFS, and OS) are solid variables that tend to be reliably reflected in patient histories. Nonetheless, one uncertainty is that there is no common pathology protocol to evaluate histopathological classification. In fact, the lack of a centralised pathology examination has been a constant limitation in conducting clinical trials addressing chemotherapy in AGC, casting clear doubts on the interpretation and applicability of 'average' results in the study population 
(Van Cutsem et al, 2006). Different studies suggest that there is significant interobserver variability in the evaluation of Lauren types, as well as the risk of misclassification in non-representative samples from endoscopic biopsies (Hansson et al, 1996; Shibata et al, 2001). Despite this, our rate of unclassified tumours is within the range reported by other authors (Polkowski et al, 1999). On the other hand, a centralised evaluation of radiological response was not performed. Nevertheless, the chemosensitivity data are compatible with the information from other similar series (Schulz et al, 2015; Al-Batran et al, 2016). Another relevant aspect is that, given the diversity of the chemotherapy regimens in this registry, we have evaluated them as drug-based groups, taking into account their common characteristics, although it is possible that the specific schedules differ somewhat in efficacy profiles, for example, dose-dependent and periodicity of the regimen. Furthermore, we have not assessed the impact of histology on second-line chemotherapy in this analysis, which could also affect OS, particularly after the introduction of ramucirumab in recent times in clinical practice.

In short, in light of the difficulty in choosing first-line chemotherapy for a patient with HER2-negative AGC, the effect of all variables that could modify response to drugs must be validated; p.g., histology. In this regard, our data support the hypothesis that histopathological heterogeneity is reflected as specific sensitivity to different cytotoxics (Koizumi et al, 2008, 2014; Ajani et al, 2009; Boku et al, 2009; Narahara et al, 2011). Consequently, we believe it is important that future clinical trial protocols with chemotherapy for AGC contemplate stratification by Lauren type.

\section{ACKNOWLEDGEMENTS}

We thank Priscilla Chase Duran for editing the manuscript. Natalia Cateriano, Miguel Vaquero, and IRICOM SA for supporting the registry website. All procedures followed were in accordance with the ethical standards of the responsible committee on human experimentation (institutional and national) and with the Helsinki Declaration of 1964 and later versions. Informed consent or a substitute for it was obtained from all patients before they were included in the study.

\section{CONFLICT OF INTEREST}

The authors declare no conflict of interest.

\section{REFERENCES}

Ajani JA, Rodriquez W, Bodoky G, Moiseyenko V, Lichinitser M, Gorbunova V, Vynnychenko I, Garin A, Lang I, Falcon S (2009) Multicenter phase III comparison of cisplatin/S-1 (CS) with cisplatin/5-FU (CF) as first-line therapy in patients with advanced gastric cancer (FLAGS): Secondary and subset analyses. In: ASCO Annual Meeting Proceedings. J Clin Oncol 27(suppl 15): 4511.

Al-Batran S-E, Hofheinz RD, Pauligk C, Kopp H-G, Haag GM, Luley KB, Meiler J, Homann N, Lorenzen S, Schmalenberg H, Probst S, Koenigsmann M, Egger M, Prasnikar N, Caca K, Trojan J, Martens UM, Block A, Fischbach W, Mahlberg R, Clemens M, Illerhaus G, Zirlik K, Behringer DM, Schmiegel W, Pohl M, Heike M, Ronellenfitsch, Schuler M, Bechstein WO, Königsrainer A, Gaiser T, Schirmacher P, Hozaeel W, Reichart A, Goetze TO, Sievert M, Jäger E, Mönig S, Tannapfel A (2016) Histopathological regression after neoadjuvant docetaxel, oxaliplatin, fluorouracil, and leucovorin versus epirubicin, cisplatin, and fluorouracil or capecitabine in patients with resectable gastric or gastro-oesophageal junction adenocarcinoma (FLOT4-AIO). Lancet Oncol 17: 1697-1708.
Bang YJ, Van Cutsem E, Feyereislova A, Chung HC, Shen L, Sawaki A, Lordick F, Ohtsu A, Omuro Y, Satoh T, Aprile G, Kulikov E, Hill J, Lehle M, Rüschoff J, Kang YK (2010) Trastuzumab in combination with chemotherapy versus chemotherapy alone for treatment of HER2-positive advanced gastric or gastro-oesophageal junction cancer (ToGA): A phase 3, open-label, randomised controlled trial. Lancet 376: 687-697.

Barraclough H, Govindan R (2010) Biostatistics primer: what a clinician ought to know: subgroup analyses. J Thorac Oncol 5: 741-746.

Boku N, Yamamoto S, Fukuda H, Shirao K, Doi T, Sawaki A, Koizumi W, Saito H, Yamaguchi K, Takiuchi H, Nasu J, Ohtsu A (2009) Fluorouracil versus combination of irinotecan plus cisplatin versus S-1 in metastatic gastric cancer: a randomised phase 3 study. Lancet Oncol 10: 1063-1069. Cancer Genome Atlas Research Network (2014) Comprehensive molecular characterization of gastric adenocarcinoma. Nature 513: 202-209.

Cancer Genome Atlas Research Network (2017) Integrated genomic characterization of oesophageal carcinoma. Nature 541: 169-175.

Carmona-Bayonas A, Jiménez-Fonseca P, Custodio A, Sánchez Cánovas M, Hernández R, Pericay C, Echavarria I, Lacalle A, Visa L,

Rodríguez Palomo A, Mangas M, Cano JM, Buxo E, Álvarez-Manceñido F, García T, Lorenzo JE, Ferrer-Cardona M, Viudez A, Azkarate A, Ramchandani A, Arias D, Longo F, López C, Sánchez Bayona R, Limón ML, Díaz-Serrano A, Fernández Montes A, Sala P, Cerdá P, Rivera F, Gallego J (2017) Anthracycline-based triplets do not improve the efficacy of platinum-fluoropyrimidine doublets in first-line treatment of advanced gastric cancer: real-world data from the AGAMENON National Cancer Registry. Gastric Cancer; e-pub ahead of print 9 April 2017; doi:10.1007/ s10120-017-0718-5.

Carmona-Bayonas A, Jiménez-Fonseca P, Lorenzo MLS, Ramchandani A, Martínez EA, Custodio A, Garrido M, Echavarría I, Cano JM, Barreto JEL, García TG, Manceñido FÁ, Lacalle A, Cardona MF, Mangas M, Visa L, Buxó E, Azkarate A, Díaz-Serrano A, Montes AF, Rivera F (2016) On the effect of triplet or doublet chemotherapy in advanced gastric cancer: results from a National Cancer Registry. J Natl Compr Canc Netw 14: 1379-1388.

Cristescu R, Lee J, Nebozhyn M, Kim K-M, Ting JC, Wong SS, Liu J, Yue YG, Wang J, Yu K (2015) Molecular analysis of gastric cancer identifies subtypes associated with distinct clinical outcomes. Nat Med 21: 449-456. Cunningham D, Starling N, Rao S, Iveson T, Nicolson M, Coxon F, Middleton G, Daniel F, Oates J, Norman AR (2008) Capecitabine and oxaliplatin for advanced esophagogastric cancer. N Engl J Med 358: 36-46.

Custodio A, Carmona-Bayonas A, Fonseca PJ, Sánchez ML, Antonio Viudez R, Hernández JM, CANO IE, Carles Pericay M, Mangas LV, Buxó E, Teresa García García AR, Plazas JG (2017) Nomogram-based prediction of survival in patients with advanced oesophagogastric adenocarcinoma receiving first-line chemotherapy: a multicenter prospective study in the era of trastuzumab. $\mathrm{Br} J$ Cancer 116: $1526-1535$.

Duo-Ji M-M, Ci-Ren B-S, Long Z-W, Zhang X-H, Luo D-L (2017) Short-term efficacy of different chemotherapy regimens in the treatment of advanced gastric cancer: a network meta-analysis. Oncotarget 8: 37896-37911.

Fleiss JL, Tytun A, Ury HK (1980) A simple approximation for calculating sample sizes for comparing independent proportions. Biometrics 36: 343-346.

Hamilton SR, Aaltonen LA (2000) Pathology and Genetics of Tumours of the Digestive System. IARC press Lyon: France.

Hansson L-E, Lindgren A, Nyrén O (1996) Can endoscopic biopsy specimens be used for reliable laurén classification of gastric cancer? Scand J Gastroenterol 31: 711-715.

Hofmann M, Stoss O, Shi D, Büttner R, Van De Vijver M, Kim W, Ochiai A, Rüschoff J, Henkel T (2008) Assessment of a HER2 scoring system for gastric cancer: results from a validation study. Histopathology 52: 797-805.

Huang D, Lu N, Fan Q, Sheng W, Bu H, Jin X, Li G, Liu Y, Li X, Sun W (2013) HER2 status in gastric and gastroesophageal junction cancer assessed by local and central laboratories: Chinese results of the HER-EAGLE study. PLOS ONE 8: e80290.

Jiménez-Fonseca P, Carmona-Bayonas A, Lorenzo MLS, Plazas JG, Custodio A, Hernández R, Garrido M, García T, Echavarría I, Cano JM (2016) Prognostic significance of performing universal HER2 testing in cases of advanced gastric cancer. Gastric Cancer 20: 465-474.

Koizumi W, Kim YH, Fujii M, Kim HK, Imamura H, Lee KH, Hara T, Chung HC, Satoh T, Cho JY, Hosaka H, Tsuji A, Takagane A, Inokuchi M, Tanabe K, Okuno T, Ogura M, Yoshida K, Takeuchi M, Nakajima T. JACCRO and KCSG Study Group (2014) Addition of docetaxel to S-1 
without platinum prolongs survival of patients with advanced gastric cancer: a randomized study (START). J Cancer Res Clin Oncol 140: 319-328.

Koizumi W, Narahara H, Hara T, Takagane A, Akiya T, Takagi M, Miyashita K, Nishizaki T, Kobayashi O, Takiyama W, Toh Y, Nagaie T, Takagi S, Yamamura Y, Yanaoka K, Orita H, Takeuchi M (2008) S-1 plus cisplatin versus S-1 alone for first-line treatment of advanced gastric cancer (SPIRITS trial): a phase III trial. Lancet Oncol 9: 215-221.

Lauren P (1965) The two histological main type of gastric cancer: diffuse and so-called intestinal-type carcinoma. An attempt at a histo-clinical classification. Acta Pathol Microbiol Scand 64: 31-49.

Lei Z, Tan IB, Das K, Deng N, Zouridis H, Pattison S, Chua C, Feng Z, Guan YK, Ooi CH, Ivanova T, Zhang S, Lee M, Wu J, Ngo A, Manesh S, Tan E, Teh BT, So JBY, Goh LK, Boussioutas A, Lim TKH, Flotow H, Tan P, Rozen SG (2013) Identification of molecular subtypes of gastric cancer with different responses to PI3-kinase inhibitors and 5-fluorouracil. Gastroenterology 145: 554-565.

Ma J, Shen H, Kapesa L, Zeng S (2016) Lauren classification and individualized chemotherapy in gastric cancer (Review). Oncol Lett 11: 2959-2964.

Narahara H, Iishi H, Imamura H, Tsuburaya A, Chin K, Imamoto H, Esaki T, Furukawa H, Hamada C, Sakata Y (2011) Randomized phase III study comparing the efficacy and safety of irinotecan plus S-1 with S- 1 alone as first-line treatment for advanced gastric cancer (study GC0301/TOP-002). Gastric Cancer 14: 72-80.

Polkowski W, van Sandick JW, Offerhaus GJ, ten Kate FJ, Mulder J, Obertop H, van Lanschot JJ (1999) Prognostic value of Laurén classification and c-erbB-2 oncogene overexpression in adenocarcinoma of the esophagus and gastroesophageal junction. Ann Surg Oncol 6: 290-297.

Schulz C, Kullmann F, Kunzmann V, Fuchs M, Geissler M, Vehling-Kaiser U, Stauder H, Wein A, Al-Batran S, Kubin T (2015) NeoFLOT: multicenter phase II study of perioperative chemotherapy in resectable adenocarcinoma of the gastroesophageal junction or gastric adenocarcinoma-very good response predominantly in patients with intestinal type tumors. Int J Cancer 137: 678-685.

Shah MA, Khanin R, Tang L, Janjigian YY, Klimstra DS, Gerdes H, Kelsen DP (2011) Molecular classification of gastric cancer: a new paradigm. Clin Cancer Res 17: 2693-2701.
Shibata A, Longacre TA, Puligandla B, Parsonnet J, Habel LA (2001) Histological classification of gastric adenocarcinoma for epidemiological research: concordance between pathologists. Cancer Epidemiol Prev Biomarkers 10: 75-78.

Simon R (1982) Patient subsets and variation in therapeutic efficacy. Br J Clin Pharmacol 14: 473-482.

Tan IB, Ivanova T, Lim KH, Ong CW, Deng N, Lee J, Tan SH, Wu J, Lee MH, Ooi CH, Rha SY, Wong WK, Boussioutas A, Yeoh KG, So J, Yong WP, Tsuburaya A, Grabsch H, Toh HC, Rozen S, Cheong JH, Noh SH, Wan WK, Ajani JA, Lee J-S, Tellez MS, Tan P (2011) Intrinsic subtypes of gastric cancer, based on gene expression pattern, predict survival and respond differently to chemotherapy. Gastroenterology 141: 476-485485-11.

Van Cutsem E, Moiseyenko VM, Tjulandin S, Majlis A, Constenla M, Boni C, Rodrigues A, Fodor M, Chao Y, Voznyi E, Risse M-L, Ajani JA (2006) Phase III study of docetaxel and cisplatin plus fluorouracil compared with cisplatin and fluorouracil as first-line therapy for advanced gastric cancer: a report of the V325 Study Group. J Clin Oncol 24: 4991-4997.

Wagner AD, Unverzagt S, Grothe W, Kleber G, Grothey A, Haerting J, Fleig WE (2010) Chemotherapy for advanced gastric cancer. Cochrane Database Syst Rev CD004064.

Yong W-P, Rha SY, Tan IB, Choo S-P, Syn N, Koh V, Tan SH, So J, Shabbir A, Tan CS, Ng MC-H, Tai DW-M, Lee MH, Wu J, Yeoh KG, Tan PBO, Kim HS (2017) Microarray-based tumor molecular profiling to direct choice of cisplatin plus S-1 or oxaliplatin plus S-1 for advanced gastric cancer: a multicentre, prospective, proof-of-concept phase 2 trial. Int J Clin Oncol 35: 2017 (Suppl 4S; Abstract 48).

Yoon C, Cho S-J, Aksoy BA, Park DJ, Schultz N, Ryeom SW, Yoon SS (2016) Chemotherapy resistance in diffuse-type gastric adenocarcinoma is mediated by RHOA activation in cancer stem-like cells. Clin Cancer Res 22: 971-983.

This work is published under the standard license to publish agreement. After 12 months the work will become freely available and the license terms will switch to a Creative Commons AttributionNonCommercial-Share Alike 4.0 Unported License.

${ }^{1}$ Department of Medical Oncology, Central de Asturias University Hospital, Oviedo 33011, Spain; ${ }^{2}$ Department of Hematology and Medical Oncology, Morales Meseguer University Hospital, Murcia 30008, Spain; ${ }^{3}$ Department of Medical Oncology, Canarias University Hospital, Tenerife 38320, Spain; ${ }^{4}$ Department of Medical Oncology, La Paz University Hospital, Madrid 28046, Spain; ${ }^{5}$ Department of Medical Oncology, Ciudad Real General Hospital, Ciudad Real 13005, Spain; ${ }^{6}$ Department of Medical Oncology, Complejo Hospitalario de Navarra, Pamplona 31008, Spain; ${ }^{7}$ Department of Medical Oncology, Gregorio Marañón University Hospital, Madrid 28007, Spain; ${ }^{8}$ Department of Medical Oncology, Parc Tauli University Hospital, Sabadell 08208, Spain; ${ }^{9}$ Department of Medical Oncology, Hospital Galdakao-Usansolo, Galdakao-Usansolo 48960, Spain; ${ }^{10}$ Department of Medical Oncology, El Mar University Hospital, Barcelona 08003, Spain; ${ }^{11}$ Department of Medical Oncology, Hospital Clinic, Barcelona 08036, Spain; ${ }^{12}$ Department of Pharmacy, Central de Asturias University Hospital, Oviedo 30008, Spain; ${ }^{13}$ Department of Medical Oncology, Son Espases University Hospital, Mallorca 07120, Spain; ${ }^{14}$ Department of Medical Oncology, Insular de Gran Canaria University Hospital, Las Palmas de Gran Canaria 35016, Spain; ${ }^{15}$ Department of Medical Oncology, Marqués de Valdecilla University Hospital, Santander 39008, Spain; ${ }^{16}$ Department of Medical Oncology, Complejo Hospitalario de Orense, Orense 32005, Spain; ${ }^{17}$ Department of Medical Oncology, Ramón y Cajal University Hospital, Madrid 28034, Spain; ${ }^{18}$ Department of Medical Oncology, Clínica Universidad de Navarra, Pamplona 31008, Spain; ${ }^{19}$ Department of Medical Oncology, Virgen del Rocío University Hospital, Sevilla 41013, Spain; ${ }^{20}$ Department of Medical Oncology, 12 de Octubre University Hospital, Madrid 28041, Spain; ${ }^{21}$ Department of Medical Oncology, Hospital San Millán-San Pedro, Logroño 26006, Spain; ${ }^{22}$ Department of Medical Oncology, Tecknon Cancer Institute, Barcelona 08022, Spain; ${ }^{23}$ Department of Medical Oncology, Pontificia Universidad Católica de Chile, Santiago de Chile, Chile and ${ }^{24}$ Department of Medical Oncology, Elche University Hospital, Elche 03203, Spain

Supplementary Information accompanies this paper on British Journal of Cancer website (http://www.nature.com/bjc) 